\title{
TNF stimulation induces VHL overexpression and impairs angiogenic potential in skeletal muscle myocytes
}

\author{
VLADIMIR T. BASIC ${ }^{1}$, ANNETTE JACOBSEN ${ }^{1,2}$, ALLAN SIRSJÖ ${ }^{1}$ and SAMY M.ABDEL-HALIM ${ }^{3}$ \\ ${ }^{1}$ Department of Clinical Medicine, Örebro University, Örebro, Sweden; ${ }^{2}$ School of Biomedical Sciences, \\ Charles Sturt University, Wagga Wagga, New South Wales, Australia; ${ }^{3}$ Division of Respiratory Medicine \\ and Allergology, Department of Clinical Sciences, Danderyd Hospital, Stockholm, Sweden
}

Received February 15, 2014; Accepted March 24, 2014

DOI: $10.3892 /$ ijmm.2014.1776

\begin{abstract}
Decreased skeletal muscle capillarization is considered to significantly contribute to the development of pulmonary cachexia syndrome (PCS) and progressive muscle wasting in several chronic inflammatory diseases, including chronic obstructive pulmonary disease (COPD). It is unclear to which extent the concurrent presence of systemic inflammation contributes to decreased skeletal muscle capillarization under these conditions. The present study was designed to examine in vitro the effects of the pro-inflammatory cytokine, tumor necrosis factor (TNF), on the regulation of hypoxiaangiogenesis signal transduction and capillarization in skeletal muscles. For this purpose, fully differentiated $\mathrm{C} 2 \mathrm{C} 12$ skeletal muscle myocytes were stimulated with TNF and maintained under normoxic or hypoxic conditions. The expression levels of the putative elements of the hypoxia-angiogenesis signaling cascade were examined using qPCR, western blot analysis and immunofluorescence. Under normoxic conditions, TNF stimulation increased the protein expression of anti-angiogenic von-Hippel Lindau (VHL), prolyl hydroxylase (PHD)2 and ubiquitin conjugating enzyme 2D1 (Ube2D1), as well as the total ubiquitin content in the skeletal muscle myocytes. By contrast, the expression levels of hypoxia-inducible factor $1-\alpha$ (HIF1- $\alpha$ ) and those of its transcriptional targets, vascular endothelial growth factor (VEGF)A and glucose transporter 1 (Glut1), were markedly reduced. In addition, hypoxia increased the expression of the VHL transcript and further elevated the VHL protein expression levels in $\mathrm{C} 2 \mathrm{C} 12$ myocytes following TNF stimulation. Consequently, an impaired angiogenic potential was observed in the TNF-stimulated myocytes during hypoxia. In conclusion, TNF increases VHL expres-
\end{abstract}

Correspondence to: Dr Vladimir T. Basic, Department of Clinical Medicine, Örebro University, Fakultetsgatan 1, Örebro 70182, Sweden E-mail: vladimir.basic@oru.se

Key words: chronic obstructive pulmonary disease, pulmonary cachexia, atrophy, capillarization, angiogenesis, von-Hippel Lindau tumor suppressor sion and disturbs hypoxia-angiogenesis signal transduction in skeletal muscle myocytes. The current findings provide a mechanism linking systemic inflammation and impaired angiogenesis in skeletal muscle. This is particularly relevant to further understanding the mechanisms mediating muscle wasting and cachexia in patients with chronic inflammatory diseases, such as COPD.

\section{Introduction}

Impaired angiogenic potential and decreased skeletal muscle capillarization are known to contribute significantly to the development of cachexia and progressive muscle wasting in several chronic inflammatory diseases, including chronic obstructive pulmonary disease (COPD) (1-6). The underlying mechanisms mediating decreased skeletal muscle capillarization under these conditions remain poorly understood.

Several inflammatory markers, part of a systemic inflammatory response, have been suggested to be important for the development of cachexia in a number of chronic disorders (7-11) amongst which, elevated serum levels of the pro-inflammatory cytokine, tumor necrosis factor (TNF), have been suggested to be of particular relevance (12). The potential contribution of TNF to the development of cachexia and decreased capillarization in a disease state as COPD remains a matter of debate, due to inconsistency in reports regarding its serum levels in patients with COPD (13-17). However, elevated circulatory TNF levels appear to be associated with muscle loss in patients with confirmed cachexia $(16,18)$, as well as with muscle atrophy and decreased capillarization in animal models of COPD (19-22). Furthermore, TNF is a potent catabolic and anti-angiogenic factor in vitro (23-26).

TNF has been demonstrated to promote a catabolic state in skeletal muscles through the activation of the ubiquitin proteolytic system (UPS) and the degradation of muscle proteins by the proteasome $(22-24,27)$. In skeletal muscle, several UPS members are known to mediate muscle wasting in diverse catabolic states. These include E3 $\alpha$, atrogin-1/MAFbx, muscle RING-finger protein 1 (MuRF1), E2(14k) and ubiquitin-specific protease $19(28,29)$. In addition, we have recently reported the overexpression of the E3 ubiquitin ligase, von-Hippel Lindau (VHL) tumor suppressor and the E2 family member, ubiquitin conjugating enzyme 2D1 (Ube2D1) in the skeletal 
muscle of patients with COPD and in a rodent model $(1,30)$. In both studies, UPS activation was accompanied by disturbed hypoxia-angiogenesis signal transduction, reduced capillarization and muscle fiber atrophy $(1,30)$.

VHL and Ube2D1 regulate muscle angiogenesis and glycolysis through the regulation of the hypoxia-inducible factor 1- $\alpha$ (HIF1- $\alpha)$, the main cellular oxygen sensor and regulator of tissue angiogenesis $(23,45)$. Intracellular HIF1- $\alpha$ levels are kept under tight control in response to the available oxygen levels (31). Under normoxic conditions, HIF-1 $\alpha$ is maintained at low levels by hydroxylation at the proline residues 402 and/ or 564 by the family of prolyl hydroxylases (PHD)1-4 and subsequent ubiquitination by VHL and Ube2D1 which facilitates its proteasomal degradation (31). By contrast, hypoxia inactivates prolyl hydroxylases and VHL, allowing HIF1- $\alpha$ to stabilize and become transcriptionally active, thus promoting angiogenesis, glycolysis and cell survival (31).

In the present study, we aimed to investigate the effects of TNF stimulation on the regulation of hypoxia-angiogenesis signal transduction and capillarization in skeletal muscle using an in vitro model of $\mathrm{C} 2 \mathrm{C} 12$ skeletal myocytes.

\section{Materials and methods}

Cell culture. C2C12 cells (Sigma-Aldrich Chemie $\mathrm{GmbH}$, Steinheim, Germany) were cultured in Dulbecco's modified Eagle's medium (DMEM) (PAA Laboratories, Vienna, Austria) supplemented with $10 \%$ foetal bovine serum (PAA Laboratories), 2 mM L-glutamine (Life Technologies, Stockholm, Sweden) and $0.1 \%$ PEST $(50 \mathrm{UI} / \mathrm{ml}$ penicillin and $50 \mu \mathrm{g} / \mathrm{ml}$ streptomycin; Life Technologies) and maintained at $37^{\circ} \mathrm{C}\left(5 \% \mathrm{CO}_{2}, 21 \% \mathrm{O}_{2}\right.$ and $\left.74 \% \mathrm{~N}_{2}\right)$ in a $\mathrm{CO}_{2}$ incubator (Binder $\mathrm{GmbH}$, Tuttlingen, Germany).

For the treatments in all the experiments, C2C12 myoblasts were seeded into collagen-coated six-well plates to a density of $3 \times 10^{5}$ cells/well. After reaching approximatelly $80-90 \%$ confluence, differentiation was induced by shiftting to DMEM containing $2 \%$ horse serum, $1 \mathrm{mM}$ L-glutamine and $0.1 \%$ PEST. The C2C12 myocytes were considered fully diffrentiated $96 \mathrm{~h}$ after the induction of differentiation.

TNF treatment and exposure to hypoxia. Fully differentiated myocytes were treated with $1-20 \mathrm{ng} / \mathrm{ml}$ concentrations of recombinant murine TNF (PeproTech, Rehovot, Israel) during a time period of 2-72 h. In the experiments involving exposure to hypoxia, fully differentiated $\mathrm{C} 2 \mathrm{C} 12$ myocytes were treated for $40 \mathrm{~h}$ with 10 and $20 \mathrm{ng} / \mathrm{ml} \mathrm{TNF}$ under normal oxygen conditions $\left(21 \% \mathrm{O}_{2}, 5 \% \mathrm{CO}_{2}\right.$ and $\left.74 \% \mathrm{~N}_{2}\right)$ and than deprived of oxygen for an additional $8 \mathrm{~h}\left(1 \% \mathrm{O}_{2}, 5 \% \mathrm{CO}_{2}\right.$ and $\left.94 \% \mathrm{~N}_{2}\right)$ at $37^{\circ} \mathrm{C}$ in a hypoxia incubator (Binder $\left.\mathrm{GmbH}\right)$.

RNA extraction and quantitative polymerase chain reaction $(q P C R)$. Total RNA was extracted using the Total RNA kit I (Omega Bio-tek, Norcross, UK). RNA was quantified using a Nanodrop spectrophotometer (ND-1000; Thermo Fisher Scientific Inc., Uppsala, Sweden). cDNA (1 $\mu \mathrm{g})$ was synthesised using a High-Capacity cDNA Reverse Transcription kit (Life Technologies). The reaction was performed as per the manufacturer's instructions using a Uno Thermoblock Thermal Cycler (Biometra, Göttingen, Germany). qPCR gene expression analysis was performed on an ABI Prism Sequence Detection System 7900HT (PE Applied Biosystems, Foster City, CA, USA). Genes targeted in the expression analysis, including VHL (Mm00494136_m1), PHD2 (Mm00459770_m1), Ube2D1 (Mm01172638_m1), vascular endothelial growth factor (VEGF; Mm01281449-m1), atrogin-1 (Mm00429593-m1), Murf-1 (Mm01185221-m1), ubiquitin (Ub; Mm02525294-m1) and glucose transporter 1 (Glut1; Mm00441480_m1) were provided as an Assay-on-Demand by PE Applied Biosystems. Gene expression analysis was normalized to the expression levels of ß2-microglobulin (Mm00446195_m1) which was selected as the most stable housekeeping control in the analyzed samples. The probes were labeled using FAM as the reporter dye and TAMRA as the quencher dye.

Each sample was analyzed in duplicate under the following conditions: $2 \mathrm{~min}$ at $50^{\circ} \mathrm{C}, 10 \mathrm{~min}$ at $95^{\circ} \mathrm{C}, 15 \mathrm{sec}$ at $95^{\circ} \mathrm{C}$ and $1 \mathrm{~min}$ at $60^{\circ} \mathrm{C}$. PCR amplification was correlated against a standard curve. Reactions were performed in MicroAmp Optical 96-well reaction plates (PE Applied Biosystems).

Western blot analysis. Whole cell lysates were prepared using radioimmunoprecipitation (RIPA) buffer $(150 \mathrm{mM} \mathrm{NaCl}$, $1 \%$ NP-40, $0.5 \%$ sodium deoxycholate, $0.1 \%$ sodium dodecyl sulfate (SDS) and $50 \mathrm{nM}$ Tris, $\mathrm{pH}$ 8.0) with a cocktail of protease inhibitors (Sigma-Aldrich Chemie $\mathrm{GmbH}$ ). The total protein concentration was measured using the Micro Bicinchoninic Acid (BCA) Protein Assay kit (Thermo Fisher Scientific Inc.) - microplate procedure. Equal amounts of total protein (30-60 $\mu \mathrm{g}$ ) were separated under reducing conditions using 8, 10 and 12\% SDS-PAGE and transferred onto PVDF membranes (Amersham/GE Life Sciences, Little Chalfont, $\mathrm{UK}$ ) in a transblot electrophoretic transfer cell (Bio-Rad Laboratories, Hercules, CA, USA). The membranes were probed overnight at $4^{\circ} \mathrm{C}$ using rabbit polyclonal anti-HIF1- $\alpha$ in a 1:1,000 dilution (Santa Cruz Biotechnology, Santa Cruz, CA, USA), rabbit polyclonal anti-VHL diluted 1:1,000 (Santa Cruz Biotechnology), rabbit polyclonal anti-VEGFA diluted 1:1,000 (Santa Cruz Biotechnology), rabbit polyclonal anti-PHD2 diluted 1:2,000 (Santa Cruz Biotechnology), rabbit polyclonal antiUbe2D1 diluted 1:1,000 (Abnova Corp., Taipei, Taiwan), rabbit polyclonal anti-ubiquitin-activating enzyme E1 (Ube1) diluted 1:1,000 (Abnova Corp.), rabbit polyclonal anti- $\alpha$-tubulin diluted 1:10,000 and rabbit polyclonal anti-ubiquitin (Sigma-Aldrich Chemie $\mathrm{GmbH}$ ) then incubated for $1 \mathrm{~h}$ at room temperature with secondary antibody (Sigma-Aldrich Chemie $\mathrm{GmbH}$ ). The membranes were developed using an enhanced chemiluminescence system (Amersham/GE Life Sciences) and exposed to Hyperfilm enhanced chemiluminescence (Amersham/GE Life Sciences). Densitometric analysis was performed using the $\mathrm{NIH}$ software package ImageJ (ImageJ 1.46j; NIH, Bethesda, MD, USA).

Immunofluorescence. Immunohistochemical analysis was performed following a previously described protocol (30) with modifications. In brief, serial transverse sections (tenmicrometers thick; AMS Biotechnology, Abingdon, UK) were deparaffinized in xylene and rehydrated in serial dilutions of ethanol followed by antigen retrieval in Tris-EDTA ( $\mathrm{pH}$ 9) buffer using a microwave for $20 \mathrm{~min}$. Following $30 \mathrm{~min}$ of permibialization in $0.3 \%$ Triton X-100 (AppliChem - BioChemica, 


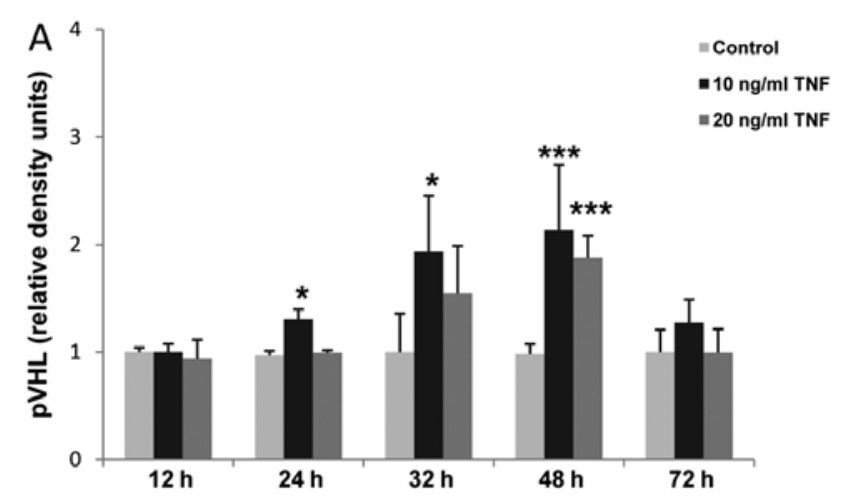

B
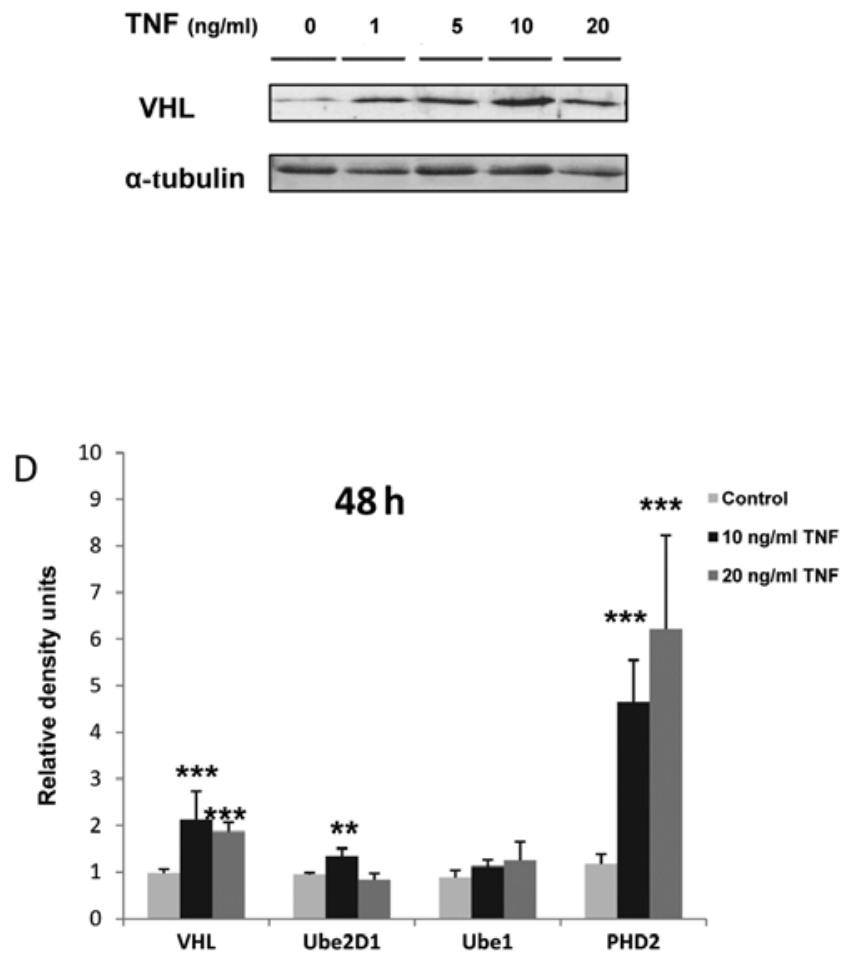

Figure 1. Tumor necrosis factor (TNF) increases the expression levels of von-Hippel Lindau (VHL), prolyl hydroxylase (PHD)2 and ubiquitin-conjugating enzyme 2D1 (Ube2D1) protein in skeletal muscle myocytes. (A) Time-dependant increase in VHL protein expression; ${ }^{*} \mathrm{P}<0.05,{ }^{* * * *} \mathrm{P}<0.001, \mathrm{n}=3$. (B) Dosedependant increase in VHL protein expression in response to TNF stimulation. (C) Representative western blot of VHL, Ube2D1, Ube1 and PHD2 expression after $48 \mathrm{~h}$ of TNF stimulation, $\mathrm{n} \geq 3$. (E) Relative VHL, Ube2D1, Ube1 and PHD2 density values. $\alpha$-tubulin was used as the loading control; ${ }^{*} \mathrm{P}<0.05,{ }^{* *} \mathrm{P}<0.01$, ${ }_{* * * * *}^{*}<0.001, \mathrm{n}=3$.

Darmstadt, Germany) solution, the sections were incubated for $1 \mathrm{~h}$ in blocking solution containing $1 \% \mathrm{BSA}$ and $10 \%$ goat serum. Thereafter, the sections were incubated with primary antibody raised against VHL, PHD2 (1:100 dilution, rabbit polyclonal, Santa Cruz Biotechnology), Ube2D1, Ube1 and Ub (1:100 dilution, rabbit polyclonal; Abnova Corp.) overnight at $4^{\circ} \mathrm{C}$.

The localization of VHL expression in the $\mathrm{C} 2 \mathrm{C} 12$ skeletal muscle myocytes was performed in eight-chambered immunocytochemical slides (Sarstedt, Nümbrecht, Germany). In brief, fully differentiated myocytes were fixed with ice-cold paraformaldehyde (4\%) for $15 \mathrm{~min}$; the fixative was removed and washed three times with PBS. Permeabilization was performed using $0.2 \%$ Triton X100 (AppliChem - BioChemica) solution in PBS for 30 min followed by incubation for $1 \mathrm{~h}$ in blocking solution containing $1 \% \mathrm{BSA}$ and $10 \%$ goat serum. The primary antibody in the dilution of 1:100 (VHL, rabbit polyclonal; Santa Cruz Biotechnology) was then added followed by incubation overnight at $4^{\circ} \mathrm{C}$.

Primary antibodies were detected following incubation with FITC-labeled secondary antibody raised in goat and directed against rabbit IgG1 $(\mathrm{H}+\mathrm{L})$ for $1 \mathrm{~h}$ at room temperature. DAPI was used to visualize the nucleus. As a negative control, the primary antibody was omitted and the cells were incubated directly with the secondary antibody. A series of photographs was taken using a fluorescent microscope (obtained from Olympus, Tokyo, Japan) and the representative field was presented.
Statistical analysis. The obtained data was normally distributed as determined by the Anderson-Darling test. The results are presented as the means \pm standard deviation (SD). Data are expressed as the means \pm SD. Statistical comparisons were performed using ANOVA followed by an independent Student's t-test. Differences were considered significant at $\mathrm{P}<0.05$. Statistical analysis was performed using SPSS v.16 software. The mumber of repetitions (n) per each experiment was equal to or higher than three.

\section{Results}

Increased expression levels of anti-angiogenic VHL, PHD2 and Ube2D1 proteins in TNF-treated skeletal muscle myocytes. The stimulation of murine skeletal muscle myocytes with TNF resulted in a dose- and time-dependant increase in the expression of VHL protein, which reached a peak after $48 \mathrm{~h}$ of stimulation and at the concentration of $10 \mathrm{ng} / \mathrm{ml} \mathrm{TNF}$ $\left({ }^{* * *} \mathrm{P}<0.001\right.$; Fig. 1A-D). In addition, the Ube2D1 protein expression was enhanced by 1.4 -fold following the stimulation of the $\mathrm{C} 2 \mathrm{C} 12$ myocytes for $48 \mathrm{~h}$ with $10 \mathrm{ng} / \mathrm{ml} \mathrm{TNF}\left({ }^{* *} \mathrm{P}<0.01\right.$; Fig. 1C and D). Concurrently, TNF stimulation induced a dosedependent increase in PHD2 protein expression (4-fold increase at $10 \mathrm{ng} / \mathrm{ml}$ and 5.3 -fold at $20 \mathrm{ng} / \mathrm{ml} \mathrm{TNF},{ }^{* * *} \mathrm{P}<0.01$; Fig. $1 \mathrm{~B}$ and C). By contrast, TNF stimulation did not significantly alter the Ube1 expression in the $\mathrm{C} 2 \mathrm{C} 12$ myocytes (Fig. 1B and C). The overexpression of free and conjugated ubiquitin in the 

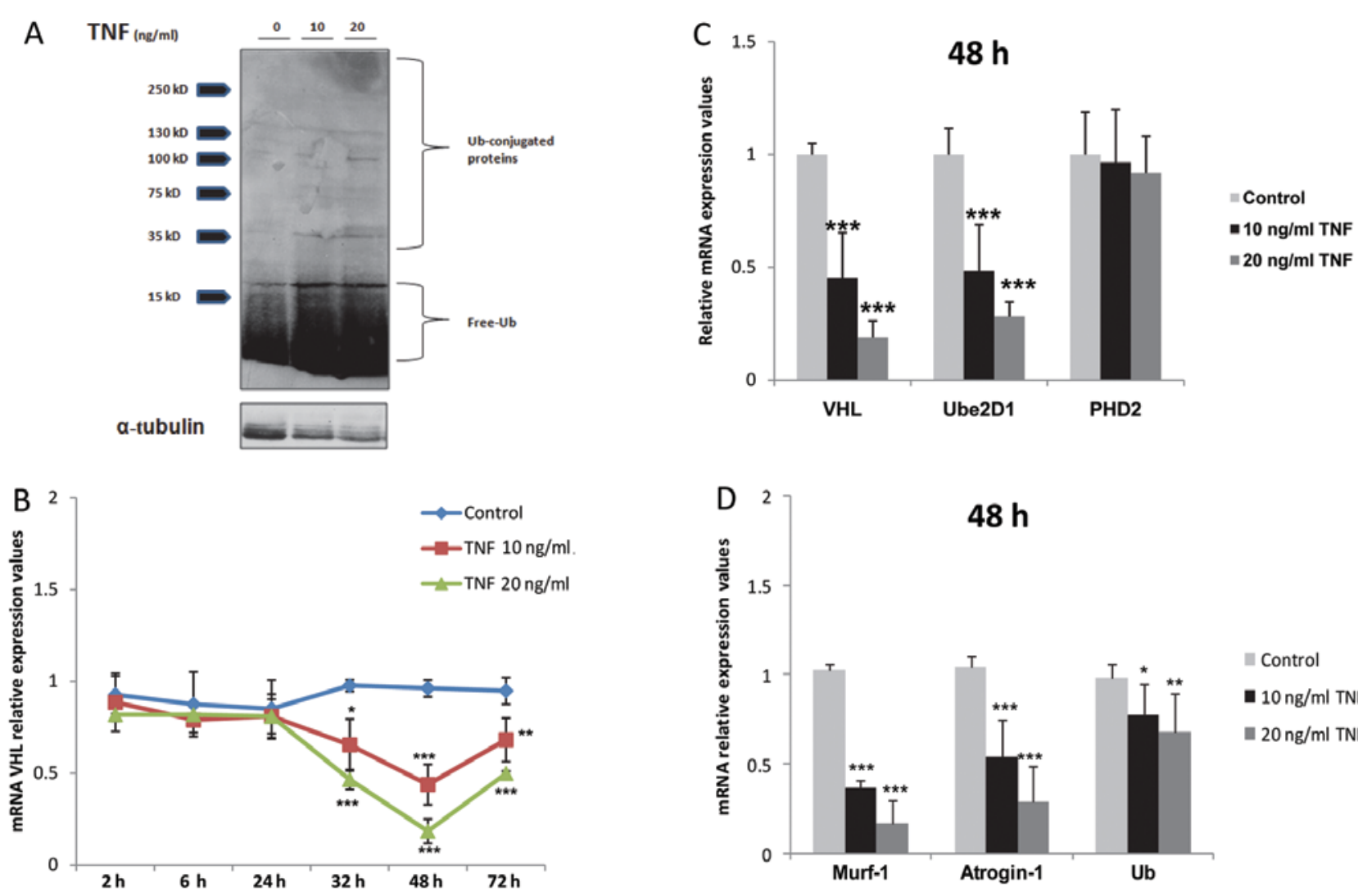

III Control

- $10 \mathrm{ng} / \mathrm{ml} \mathrm{TNF}$

$20 \mathrm{ng} / \mathrm{ml} \mathrm{TNF}$

Figure 2. Prolonged tumor necrosis factor (TNF) stimulation suppresses the transcription of von-Hippel Lindau (VHL) and other atrophy-mediating genes in skeletal muscle myocytes. (A) Increased levels of free ubiquitin (Ub) and Ub-conjugated protein in TNF-treated myocytes. (B) Time curve qPCR analysis of mRNA VHL expression, ${ }^{*} \mathrm{P}<0.05,{ }^{* *} \mathrm{P}<0.01,{ }^{* * * *} \mathrm{P}<0.001, \mathrm{n}=3$. (C) qPCR analysis of VHL, ubiquitin conjugating enzyme 2D1 (Ube2D1) and prolyl hydroxylase (PHD) 2 mRNA expression after $48 \mathrm{~h}$ of TNF stimulation, ${ }^{* * *} \mathrm{P}<0.001, \mathrm{n}=3$. (D) $\mathrm{qPCR}$ analysis of atrogin-1, Murf-1 and Ub mRNA expression, ${ }^{*} \mathrm{P}<0.05$, ${ }^{* * *} \mathrm{P}<0.01,{ }^{* * *} \mathrm{P}<0.001, \mathrm{n}=3$. Time duration of treatment was $48 \mathrm{~h}$.

TNF-treated myocytes in response to TNF stimulation was also confirmed by western blot analysis (Fig. 2A).

VHL, PHD2 and Ube2D1 protein overexpression in the $T N F$-treated myocytes is not a result of an enhanced transcription. VHL, Ube2D1 and PHD2 protein overexpression in the TNF-stimulated myocytes was not the result of an enhanced transcription, as determined by TaqMan PCR assays. Hence, a dose- and time-dependant downregulation in VHL mRNA expression in the TNF-treated myocytes, peaking after $48 \mathrm{~h}$ of stimulation $\left({ }^{*} \mathrm{P}<0.05,{ }^{* *} \mathrm{P}<0.01,{ }^{* * *} \mathrm{P}<0.001 ; \mathrm{n}=3\right.$; Fig. $2 \mathrm{~B}$ and $\left.\mathrm{C}\right)$ was observed. Similarly, treatment with TNF decreased Ube2D1 mRNA expression $\left({ }^{* * *} \mathrm{P}<0.001, \mathrm{n}=3\right.$; Fig. $\left.2 \mathrm{C}\right)$, while the mRNA expression of PHD2 was not altered significantly following treatment with TNF ( $>>0.05, n=3$; Fig. 2C). In analogy to VHL, our results demonstrated the downregulation of atrogin-1, Murf-1 and ubiquitin mRNA expression under the same conditions $\left({ }^{*} \mathrm{P}<0.05,{ }^{* *} \mathrm{P}<0.01,{ }^{* * *} \mathrm{P}<0.001 ; \mathrm{n}=3\right.$; Fig. 2D).

Nuclear localization of VHL and associated UPS members in murine skeletal muscle cells. In order to gain a better understanding of how VHL interacts with its partner proteins and exerts its E3 ligase activity in skeletal muscle tissue, we assessed the distribution and localization of VHL, Ube2D1, PHD2, Ubel and Ub expression in the murine tibialis anterior muscle. Our results demonstrated a predominant nuclear local- ization of VHL, PHD2, Ube1 and Ub expression in the murine tibialis anterior muscle (Figs. 3A and B; 4A and B), while Ube2D1 expression was not detected following the described protocol. In addition, the nuclear localization of VHL was been confirmed in the differentiated $\mathrm{C} 2 \mathrm{C} 12$ myocytes by immnucytochemistry (Fig. 5).

TNF disturbs hypoxia-angiogenesis signal transduction in skeletal muscle myocytes. Treatment with TNF induced a moderate decrease in HIF1- $\alpha$ protein expression in the $\mathrm{C} 2 \mathrm{C} 12$ myocytes (Fig. 6A), as well as a significant decrease in the expression of HIF1- $\alpha$ transcriptional targets, including VEGFA and Glut1 $\left({ }^{* * *} \mathrm{P}<0.001, \mathrm{n}=3\right.$; Fig. $6 \mathrm{C}$ and $\left.\mathrm{D}\right)$. In line with these findings, VEGF protein levels were markedly reduced (Fig. 6B).

Hypoxia increases VHL transcript levels and augments VHL protein expression in TNF-stimulated skeletal muscle myocytes. The exposure of the myocytes to hypoxia increased VHL mRNA levels in a time-dependant manner, reaching a peak after $8 \mathrm{~h}$ (2-fold, ${ }^{* * *} \mathrm{P}<0.001, \mathrm{n}=5$; Fig. 7C) and returned to basal levels after $24 \mathrm{~h}$ (Fig. 7C). This increase was also accompanied by the overexpression of VHL protein detected after $8 \mathrm{~h}$ of exposure to hypoxia (Fig. 7A, B and D). In addition, hypoxia recovered VHL mRNA expression to the basal levels and enhanced VHL protein expression in the TNF-stimulated myocytes (Fig. 7B and D). 

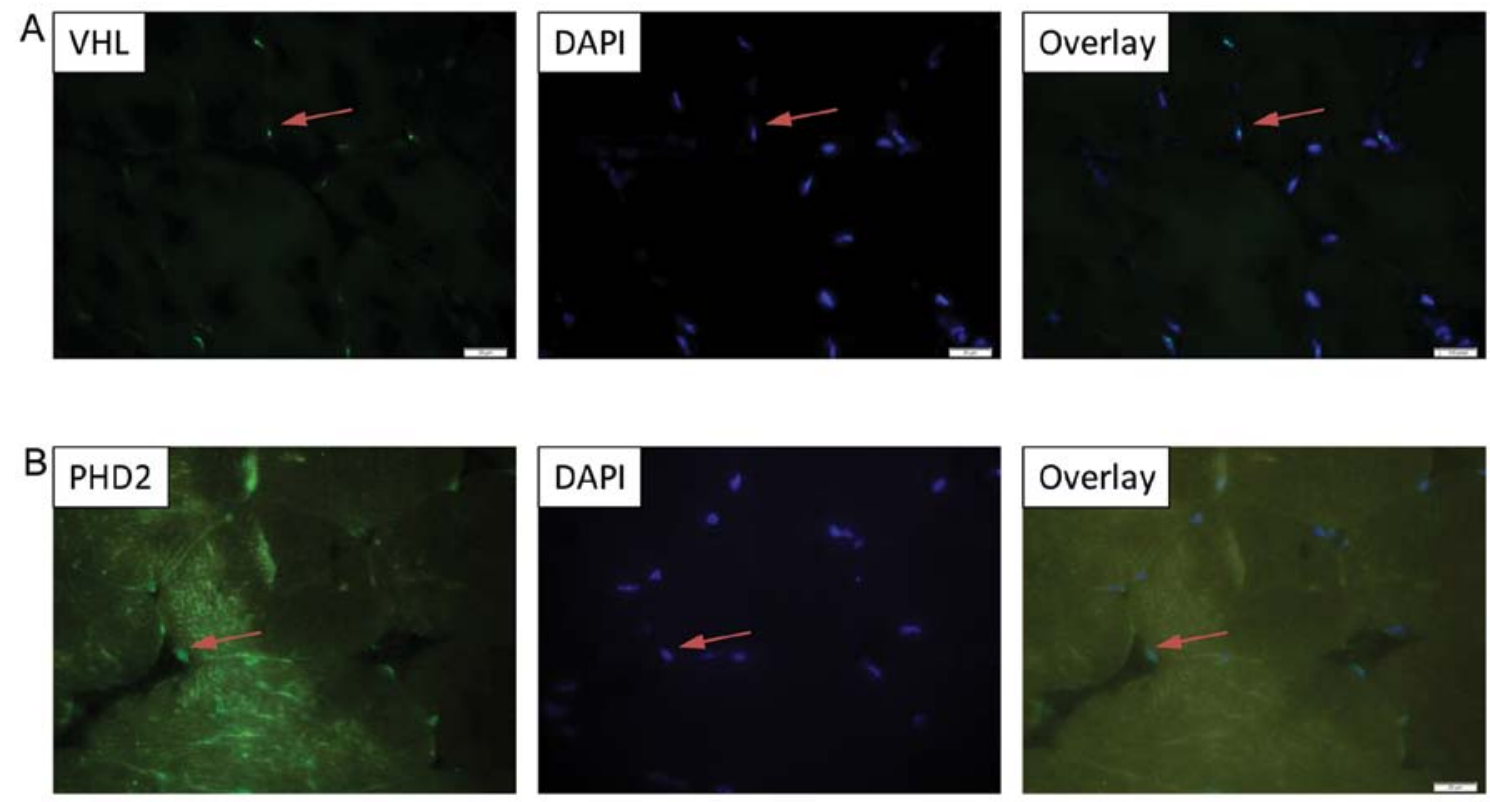

Figure 3. Nuclear localization of von-Hippel Lindau (VHL) and prolyl hydroxylase (PHD)2 protein in murine tibialis anterior muscle. (A) Green, VHL; blue, DAPI. Arrow indicates VHL-positive nuclei; (B) Green, PHD2; blue, DAPI. Arrow indicates PHD2-positive nuclei.
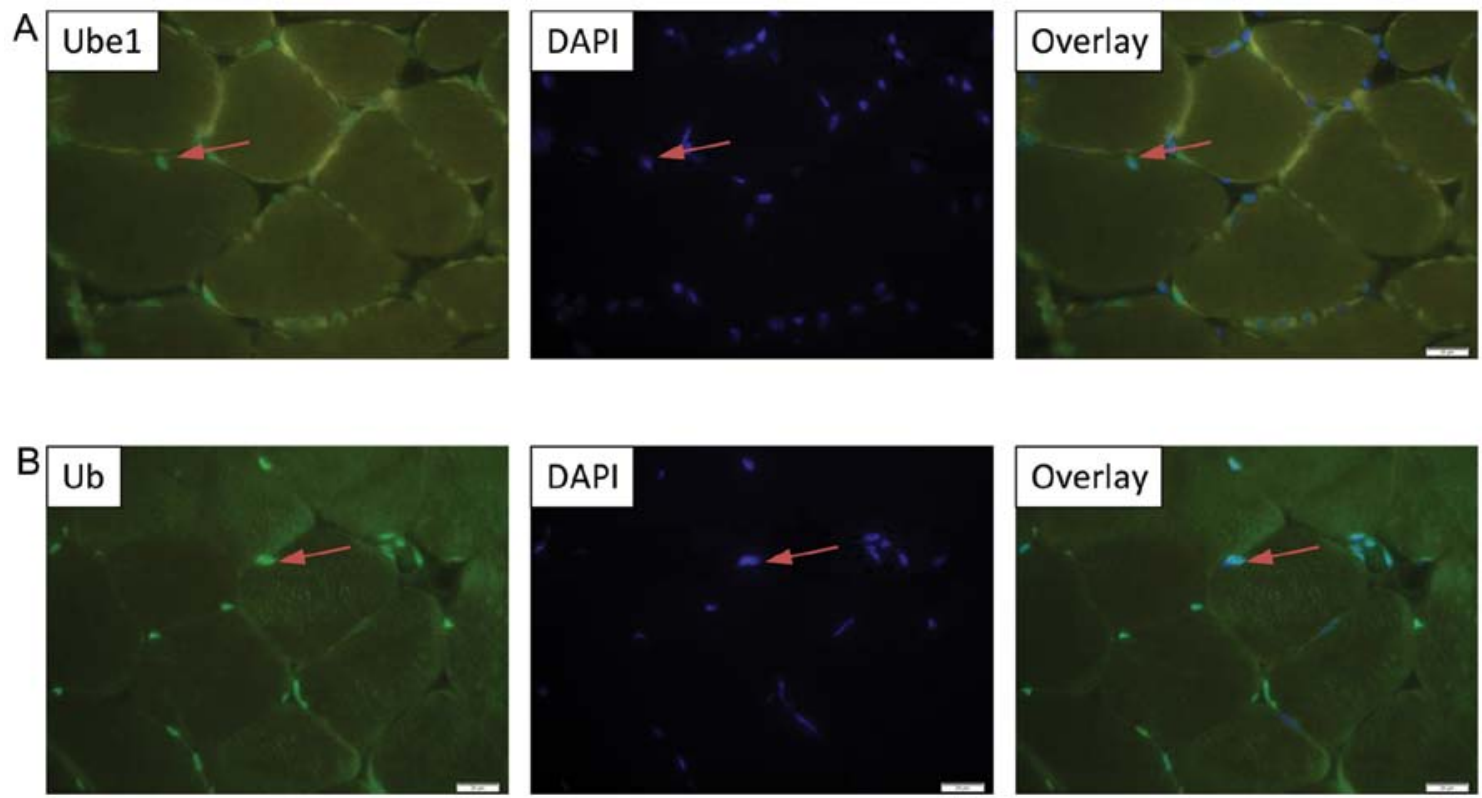

Figure 4. Nuclear localization of ubiquitin-activating enzyme E1 (Ube1) and ubiquitin (Ub) protein in murine tibialis anterior muscle. (A) Green, Ube1; blue, DAPI. Arrow indicates Ube1-positive nuclei; (B) Green, Ub; blue, DAPI. Arrow indicates Ub- positive nuclei.
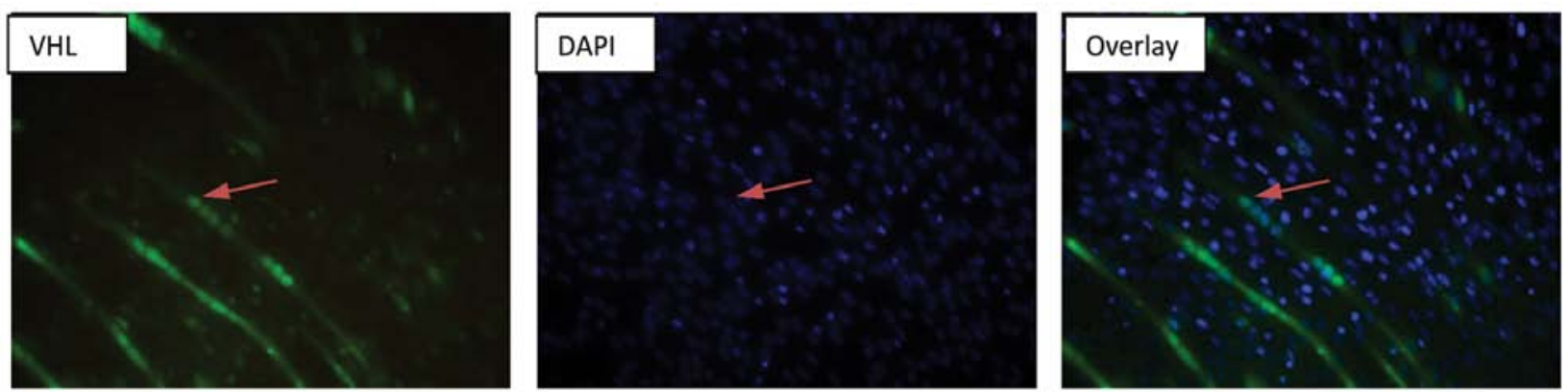

Figure 5. Von-Hippel Lindau VHL protein is predominantly localized to the nuclei in C2C12 muscle myocytes. Green, VHL; blue, DAPI. Arrow indicates VHL-positive nuclei. 

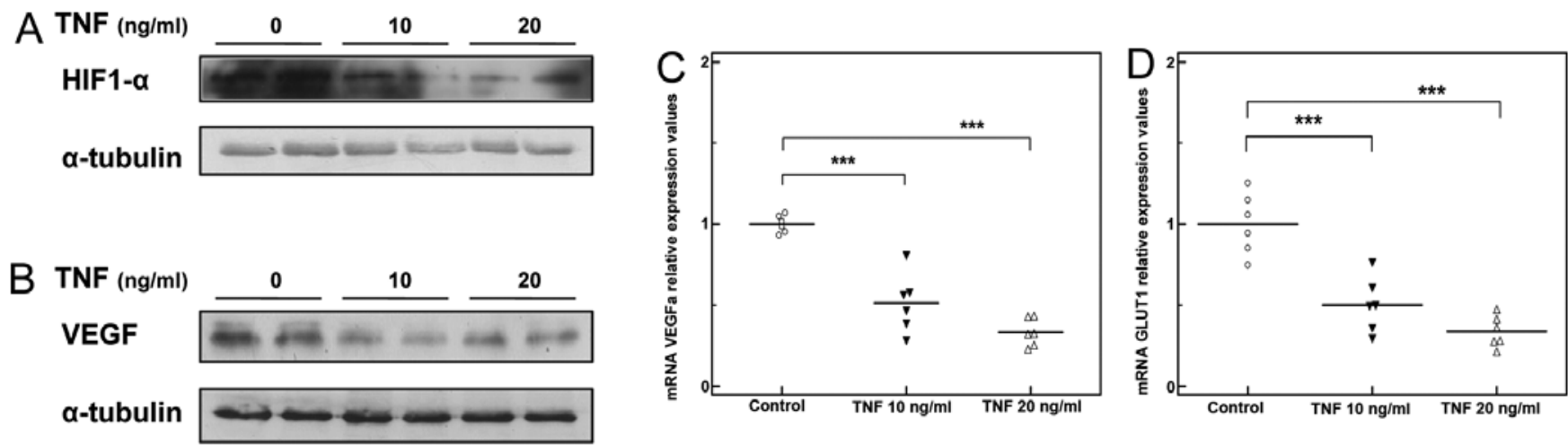

Figure 6. Tumor necrosis factor (TNF) disturbs hypoxia-angiogenesis signal transduction in C2C12 myocytes. (A) Representative western blot of hypoxiainducible factor 1- $\alpha$ (HIF1- $\alpha$ ) expression in response to $48 \mathrm{~h}$ of TNF stimulation, $\mathrm{n}=3$. (B) Representative western blot of vascular endothelial growth factor $\mathrm{A}$ (VEGFA) expression $48 \mathrm{~h}$ after stimulation, $\mathrm{n}=3$. (C) qPCR analysis of mRNA VEGFA expression $48 \mathrm{~h}$ after stimulation, ${ }^{* * * *} \mathrm{P}<0.001, \mathrm{n}=3$. (D) $\mathrm{qPCR}$ analysis of mRNA glucose transporter 1 (Glut1) expression $48 \mathrm{~h}$ after stimulation, ${ }^{* * *} \mathrm{P}<0.001, \mathrm{n}=3$.

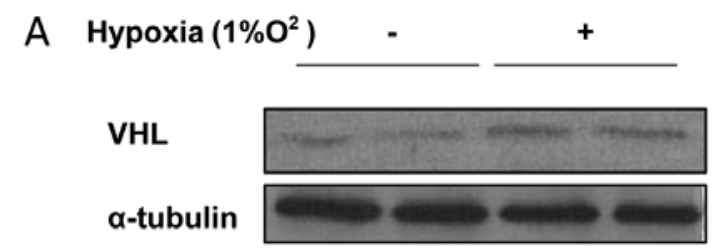

B

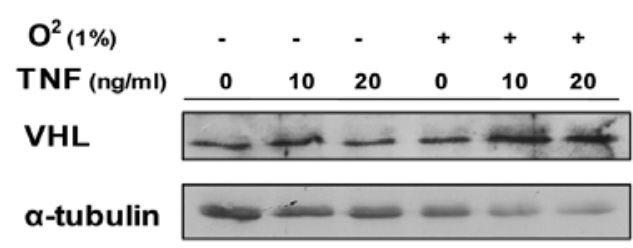

D

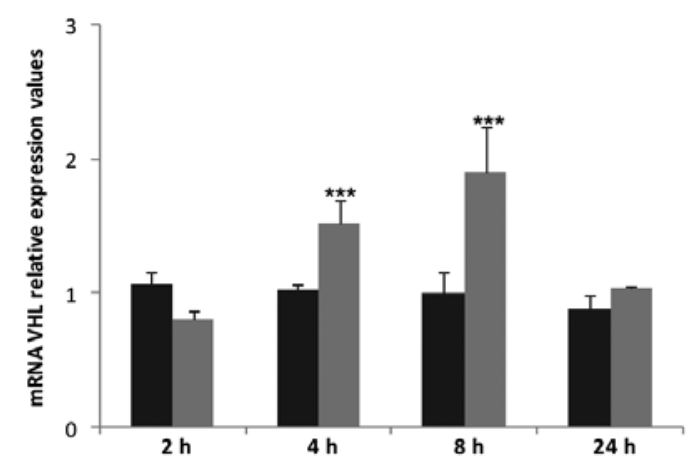

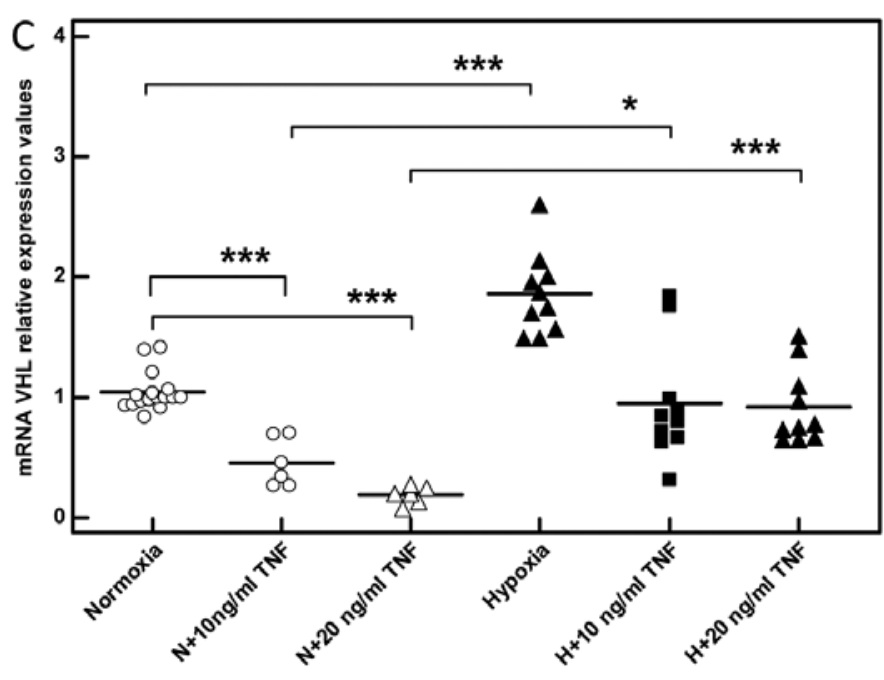

$\mathrm{E}$

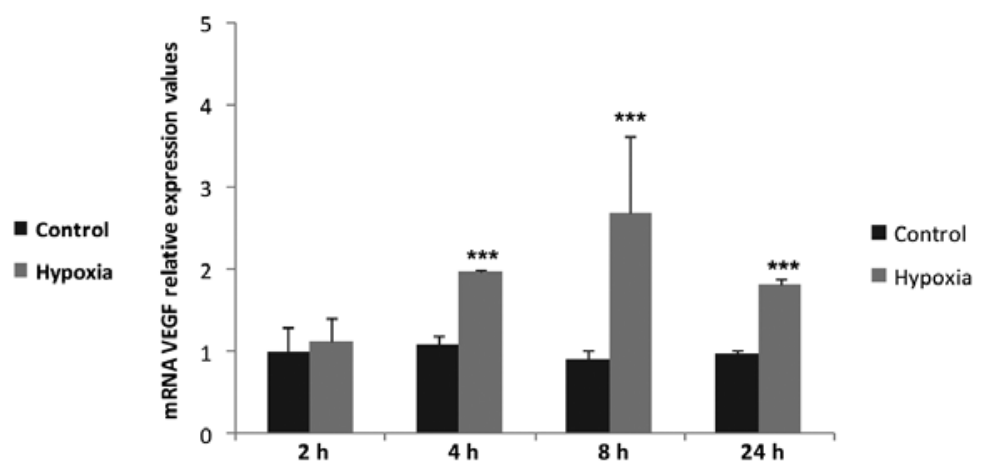

Figure 7. Hypoxia increases the expression of von-Hippel Lindau (VHL) transcript and augments VHL protein overexpression in tumor necrosis factor (TNF)stimulated $\mathrm{C} 2 \mathrm{C} 12$ muscle myocytes. (A) Representative western blot of VHL expression in C2C12 myocytes after $8 \mathrm{~h}$ of exposure to hypoxia. Normoxic conditions $\left(21 \% \mathrm{O}_{2}\right)$ are marked with a minus (-) sign. Hypoxic conditions $\left(1 \% \mathrm{O}_{2}\right)$ are marked with a plus sign (+). (B) TNF augments VHL protein overexpression in TNF-treated $\mathrm{C} 2 \mathrm{C} 12$ myocytes. Normoxic conditions $\left(21 \% \mathrm{O}_{2}\right)$ are marked with a minus (-) sign. Hypoxic conditions $\left(1 \% \mathrm{O}_{2}\right)$ are marked with a plus sign (+). Time duration of exposure to hypoxia was $8 \mathrm{~h}, \mathrm{n}=3$. (C) qPCR analysis of mRNA VHL expression $8 \mathrm{~h}$ after TNF stimulation, ${ }^{*} \mathrm{P}<0.05,{ }^{* *} \mathrm{P}<0.01$, ${ }^{* * * *} \mathrm{P}<0.001, \mathrm{n}=5 ; \mathrm{N}$, normoxia conditions $\left(21 \% \mathrm{O}_{2}\right) ; \mathrm{H}$, hypoxia conditions $\left(1 \% \mathrm{O}_{2}\right)$. (D) Time curve representing mRNA VHL expression in C2C12 myocytes exposed to hypoxia, ${ }^{* * *} \mathrm{P}<0.01, \mathrm{n}=3$. (E) Time curve representing mRNA VEGF expression in $\mathrm{C} 2 \mathrm{C} 12$ myocytes exposed to hypoxia, ${ }^{* * *} \mathrm{P}<0.01, \mathrm{n}=3$.

TNF impairs the angiogenic response of skeletal muscle myocytes exposed to hypoxia. As expected, exposing skeletal muscle myocytes to hypoxia induced an angiogenic response mirrored by increased VEGF transcription which reached 

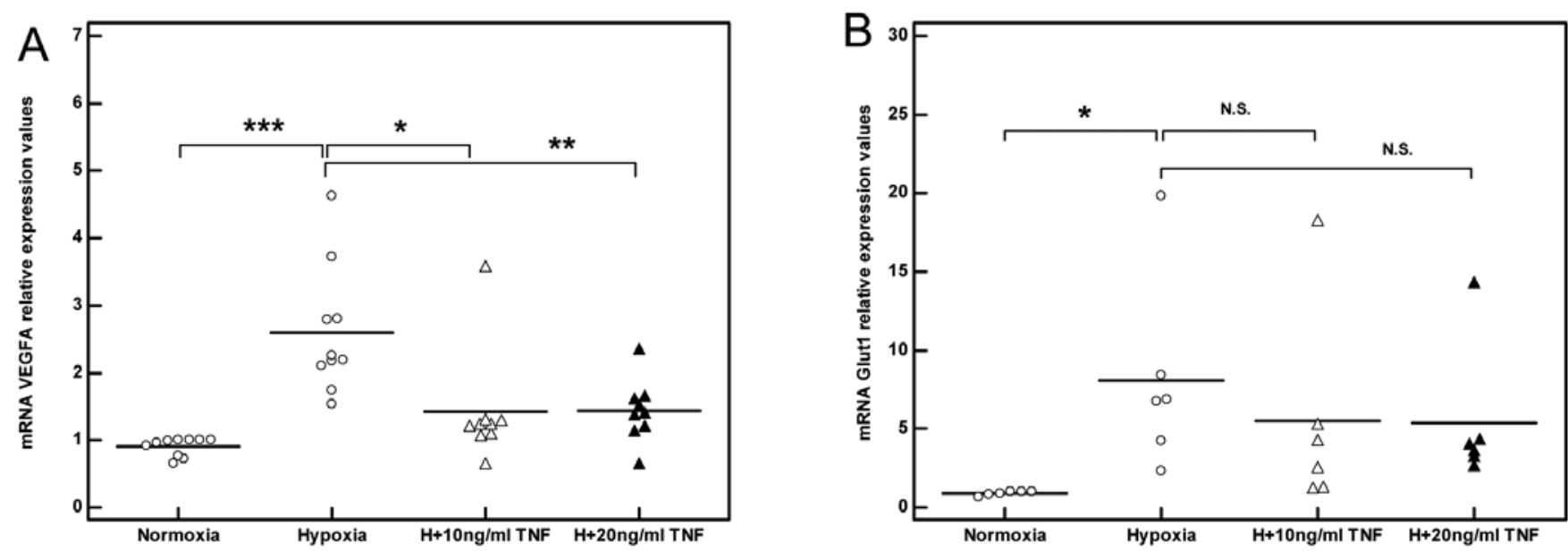

Figure 8. Tumor necrosis factor (TNF) impairs angiogenic response of $\mathrm{C} 2 \mathrm{C} 12$ myocytes to hypoxia. (A) qPCR analysis of mRNA vascular endothelial growth factor A (VEGFA) expression, ${ }^{*} \mathrm{P}<0.05,{ }^{* *} \mathrm{P}<0.01,{ }^{* * *} \mathrm{P}<0.001, \mathrm{n}=5$. (B) qPCR analysis of mRNA glucose transporter 1 (Glut1) expression, N.S., not significant; ${ }^{*} \mathrm{P}<0.05, \mathrm{n}=3$.

a peak level after 8 h (3-fold, ${ }^{* * *} \mathrm{P}<0.001, \mathrm{n}=3$; Fig. 7E). Stimulation with TNF in the presence of hypoxia failed to induce a significant angiogenic response to hypoxia as reflected by the decreased induction of VEGF mRNA levels relative to the non-stimulated myocytes (Fig. 8A). Concurrently, a trend towards decreased Glut1 induction in response to hypoxia was also observed in the TNF-stimulated myocytes (Fig. 8B).

\section{Discussion}

We have previously demonstrated enhanced VHL expression and the disturbance of hypoxia-angiogenesis signal transduction in skeletal muscle of patients with COPD (1). This observation was further confirmed in a murine model exposed to cigarette smoke $(1,30)$. However, the mechanisms mediating VHL overexpression in skeletal muscle remain unclear. The results of the current study demonstrate that the pro-inflammatory cytokine, TNF, increases VHL expression in skeletal muscle myocytes and that this effect is further augmented in the presence of hypoxia.

TNF has been reported to trigger muscle catabolism through the NF- $\mathrm{NB}$ transcription factor (32), which rapidly enhances the transcription of E3 ubiquitin ligases, such as atrogin-1/MAFbx and MuRF1, and increases the levels of free ubiquitin, which in turn potently mediate the degradation of muscle contractile proteins $(23,27,33,34)$. By contrast, the results of the current study demonstrate that TNF increases VHL expression through a mechanism which is transcriptionindependent, involving the enhanced translation/stabilization of the VHL protein. In accordance with this, TNF has been associated with protein stabilization and enhanced translation of different members of UPS through a wide range of post-translational modifications and diverse signaling pathways (35-38). Moreover, prolonged TNF stimulation resulted in a significant downregulation in VHL mRNA expression levels in skeletal muscle myocytes, as well as in the transcript levels of Ube2D1, atrogin-1, MURF-1 and the ubiquitin (Ub) gene. These results are in agreement with the studies by
Alvarez et al (37) and Bhatnagar et al (39), demonstrating the suppressed transcription of atrophy-mediating UPS genes in $\mathrm{C} 2 \mathrm{C} 12$ myocytes in response to prolonged TNF stimulation and excessive UPS activation. It can be speculated that the excessive accumulation/stabilization of the VHL protein by TNF treatment may have induced a feedback mechanism further restricting the accumulation of VHL protein, as well as an attempt of myocytes to restrict excessive VHL E3 ligase activity and the degradation of vital proteins.

Concurrent to the increase in the VHL levels, the overexpression of PHD2 and Ube2D1 protein, additionally suggested that TNF treatment enhances E3 ligase activity of the VHL ubiquitination complex in skeletal muscle myocytes. This was supported by the decreased protein stability and transcriptional efficiency of HIF1- $\alpha$ observed in this study. In line with our results, TNF has been previously reported to enhance VHL-HIF1- $\alpha$ interaction and increase HIF1- $\alpha$ ubiquitination under normoxic conditions (40). Furthermore, TNF has been associated with reduced VEGF expression and signaling in different cell lines $(22,37,38)$, as well as with a reduction in muscle VEGF levels (15) and decreased capillarization in vivo $(15,39)$.

Another highly relevant finding in this study was that hypoxia regulates VHL expression in skeletal muscle cells. Hypoxia has previously been reported to enhance VHL gene expression in non-muscle cell lines as part of a feedback mechanism and HIF1- $\alpha$ self-regulation $(42,43)$. In agreement with this, we observed a similar expression pattern between VHL and VEGF, which reached a peak after $8 \mathrm{~h}$ of exposure to hypoxia. This strongly suggests that under normal conditions, VHL functions to fine-tune HIF1- $\alpha$ signaling and prevent excessive angiogenic response in skeletal muscle myocytes. However, our data suggest that this balance is disturbed in the presence of TNF due to the elevated VHL expression, which in turn causes the impaired angiogenic adaptation of skeletal muscle myocytes to hypoxia. This finding is of particular relevance when viewed in light of our previous findings of enhanced VHL expression in patients with COPD (1) and mice 
exposed to cigarette smoke (30), as well as the reduced muscle angiogenic potential and systemic inflammatory response known to occur in patients with COPD $(5,6,13,15)$.

Taken together, the results of the current study provide evidence that elevated TNF levels disturb hypoxia-angiogenic signaling in skeletal muscles through a mechanism that involves increased VHL expression and an excessive degradation of HIF1- $\alpha$ protein. The current findings provide a mechanism linking systemic inflammation and impaired angiogenesis in skeletal muscle. This is of particular relevance in understanding the mechanisms mediating muscle wasting and cachexia in patients with chronic inflammatory diseases, such as COPD.

\section{Acknowledgements}

This study was supported by the Olle Engkvist Byggmästare Fund, Sweden (to S.A.-H.) and Örebro University grant for doctoral students (to V.T.B.).

\section{References}

1. Jatta K, Eliason G, Portela-Gomes GM, et al: Overexpression of von Hippel-Lindau protein in skeletal muscles of patients with chronic obstructive pulmonary disease. J Clin Pathol 62: 70-76, 2009.

2. Jobin J, Maltais F, Doyon JF, et al: Chronic obstructive pulmonary disease: capillarity and fiber-type characteristics of skeletal muscle. J Cardiopulm Rehabil 18: 432-437, 1998.

3. Prior SJ, McKenzie MJ, Joseph LJ, et al: Reduced skeletal muscle capillarization and glucose intolerance. Microcirculation 16 : 203-212, 2009.

4. Kivela R, Silvennoinen M, Touvra AM, Lehti TM, Kainulainen H and Vihko V: Effects of experimental type 1 diabetes and exercise training on angiogenic gene expression and capillarization in skeletal muscle. FASEB J 20: 1570-1572, 2006.

5. Gouzi F, Prefaut C, Abdellaoui A, et al: Blunted muscle angiogenic training-response in COPD patients versus sedentary controls. Eur Respir J 41: 806-814, 2013.

6. Gagnon P, Lemire BB, Dube A, et al: Preserved function and reduced angiogenesis potential of the quadriceps in patients with mild COPD. Respir Res 15: 4, 2014.

7. Gan WQ, Man SF, Senthilselvan A and Sin DD: Association between chronic obstructive pulmonary disease and systemic inflammation: a systematic review and a meta-analysis. Thorax 59: 574-580, 2004.

8. Petersen AM, Penkowa M, Iversen M, et al: Elevated levels of IL-18 in plasma and skeletal muscle in chronic obstructive pulmonary disease. Lung 185: 161-171, 2007.

9. Van Helvoort HA, Heijdra YF, Thijs HM, Vina J, Wanten GJ and Dekhuijzen PN: Exercise-induced systemic effects in muscle-wasted patients with COPD. Med Sci Sports Exerc 38: 1543-1552, 2006.

10. Deans C and Wigmore SJ: Systemic inflammation, cachexia and prognosis in patients with cancer. Curr Opin Clin Nutr Metab Care 8: 265-269, 2005.

11. Morley JE, Thomas DR and Wilson MM: Cachexia: pathophysiology and clinical relevance. Am J Clin Nutr 83: 735-743, 2006.

12. Delano MJ and Moldawer LL: The origins of cachexia in acute and chronic inflammatory diseases. Nutr Clin Pract 21: 68-81, 2006.

13. Piehl-Aulin K, Jones I, Lindvall B, Magnuson A and Abdel-Halim SM: Increased serum inflammatory markers in the absence of clinical and skeletal muscle inflammation in patients with chronic obstructive pulmonary disease. Respiration 78 191-196, 2009.

14. Wagner PD: Possible mechanisms underlying the development of cachexia in COPD. Eur Respir J 31: 492-501, 2008.

15. Garcia-Rio F, Miravitlles M, Soriano JB, et al: Systemic inflammation in chronic obstructive pulmonary disease: a population-based study. Respir Res 11: 63, 2010.
16. Pinto-Plata V, Casanova $\mathrm{C}$, Mullerova $\mathrm{H}$, et al: Inflammatory and repair serum biomarker pattern: association to clinical outcomes in COPD. Respir Res 13: 71, 2012.

17. Tanni SE, Pelegrino NR, Angeleli AY, Correa C and Godoy I: Smoking status and tumor necrosis factor-alpha mediated systemic inflammation in COPD patients. J Inflamm (Lond) 7: 29, 2010.

18. Eagan TM, Gabazza EC, D'Alessandro-Gabazza C, et al: TNF-alpha is associated with loss of lean body mass only in already cachectic COPD patients. Respir Res 13: 48, 2012.

19. Caron MA, Morissette MC, Theriault ME, Nikota JK, Stampfli MR and Debigare R: Alterations in skeletal muscle cell homeostasis in a mouse model of cigarette smoke exposure. PLoS One 8: e66433, 2013.

20. Tang K, Wagner PD and Breen EC: TNF-alpha-mediated reduction in PGC-1alpha may impair skeletal muscle function after cigarette smoke exposure. J Cell Physiol 222: 320-327, 2010.

21. Gosker HR, Langen RC, Bracke KR, et al: Extrapulmonary manifestations of chronic obstructive pulmonary disease in a mouse model of chronic cigarette smoke exposure. Am J Respir Cell Mol Biol 40: 710-716, 2009.

22. Langen RC, Schols AM, Kelders MC, van der Velden JL, Wouters EF and Janssen-Heininger YM: Muscle wasting and impaired muscle regeneration in a murine model of chronic pulmonary inflammation. Am J Respir Cell Mol Biol 35: 689-696, 2006.

23. Garcia-Martinez C, Agell N, Llovera M, Lopez-Soriano FJ and Argiles JM: Tumour necrosis factor-alpha increases the ubiquitinization of rat skeletal muscle proteins. FEBS Lett 323: 211-214, 1993.

24. Garcia-Martinez C, Llovera M, Agell N, Lopez-Soriano FJ and Argiles JM: Ubiquitin gene expression in skeletal muscle is increased during sepsis: involvement of TNF-alpha but not IL-1. Biochem Biophys Res Commun 217: 839-844, 1995.

25. Langen RC, Van Der Velden JL, Schols AM, Kelders MC, Wouters EF and Janssen-Heininger YM: Tumor necrosis factor-alpha inhibits myogenic differentiation through MyoD protein destabilization. FASEB J 18: 227-237, 2004.

26. Frater-Schroder M, Risau W, Hallmann R, Gautschi P and Bohlen P: Tumor necrosis factor type alpha, a potent inhibitor of endothelial cell growth in vitro, is angiogenic in vivo. Proc Natl Acad Sci USA 84: 5277-5281, 1987.

27. Cao PR, Kim HJ and Lecker SH: Ubiquitin-protein ligases in muscle wasting. Int J Biochem Cell Biol 37: 2088-2097, 2005.

28. Lecker SH, Solomon V, Price SR, Kwon YT, Mitch WE and Goldberg AL: Ubiquitin conjugation by the $\mathrm{N}$-end rule pathway and mRNAs for its components increase in muscles of diabetic rats. J Clin Invest 104: 1411-1420, 1999.

29. Combaret L, Adegoke OA, Bedard N, Baracos V, Attaix D and Wing SS: USP19 is a ubiquitin-specific protease regulated in rat skeletal muscle during catabolic states. Am J Physiol Endocrinol Metab 288: E693-E700, 2005.

30. Basic VT, Tadele E, Elmabsout AA, et al: Exposure to cigarette smoke induces overexpression of von Hippel-Lindau tumor suppressor in mouse skeletal muscle. Am J Physiol Lung Cell Mol Physiol 303: L519-L527, 2012.

31. Semenza GL: Regulation of oxygen homeostasis by hypoxia-inducible factor 1. Physiology (Bethesda) 24: 97-106, 2009.

32. Li YP, Schwartz RJ, Waddell ID, Holloway BR and Reid MB: Skeletal muscle myocytes undergo protein loss and reactive oxygen-mediated NF-kappaB activation in response to tumor necrosis factor alpha. FASEB J 12: 871-880, 1998.

33. Adams V, Mangner N, Gasch A, et al: Induction of MuRF1 is essential for TNF-alpha-induced loss of muscle function in mice. J Mol Biol 384: 48-59, 2008.

34. Pijet B, Pijet M, Litwiniuk A, Gajewska M, Pajak B and Orzechowski A: TNF- alpha and IFN-s-dependent muscle decay is linked to NF-kappaB- and STAT-1alpha-stimulated Atrogin1 and MuRF1 genes in C2C12 myotubes. Mediators Inflamm 2013: $171437,2013$.

35. Tong X, Buelow K, Guha A, Rausch R and Yin L: USP2a protein deubiquitinates and stabilizes the circadian protein CRY1 in response to inflammatory signals. J Biol Chem 287: 25280-25291, 2012.

36. Shukla R, Yue J, Siouda M, et al: Proinflammatory cytokine TNF-alpha increases the stability of hepatitis B virus X protein through NF-kappaB signaling. Carcinogenesis 32: 978-985, 2011 . 
37. Alvarez B, Quinn LS, Busquets S, Lopez-Soriano FJ and Argiles JM: Direct effects of tumor necrosis factor alpha (TNF-alpha) on murine skeletal muscle cell lines. Bimodal effects on protein metabolism. Eur Cytokine Netw 12: 399-410, 2001.

38. Plaisance I, Morandi C, Murigande $\mathrm{C}$ and Brink M: TNF-alpha increases protein content in $\mathrm{C} 2 \mathrm{C} 12$ and primary myotubes by enhancing protein translation via the TNF-R1, PI3K, and MEK. Am J Physiol Endocrinol Metab 294: E241-E250, 2008.

39. Bhatnagar S, Panguluri SK, Gupta SK, Dahiya S, Lundy RF and Kumar A: Tumor necrosis factor-alpha regulates distinct molecular pathways and gene networks in cultured skeletal muscle cells. PLoS One 5: e13262, 2010.

40. Zhou J, Schmid T and Brune B: Tumor necrosis factor-alpha causes accumulation of a ubiquitinated form of hypoxia inducible factor-1alpha through a nuclear factor-kappaB-dependent pathway. Mol Biol Cell 14: 2216-2225, 2003.
41. Terasaki H, Kase S, Shirasawa M, et al: TNF-alpha decreases VEGF secretion in highly polarized RPE cells but increases it in non-polarized RPE cells related to crosstalk between JNK and NF-kappaB pathways. PLoS One 8: e69994, 2013.

42. Turcotte S, Desrosiers RR and Beliveau R: Hypoxia upregulates von Hippel-Lindau tumor-suppressor protein through RhoA-dependent activity in renal cell carcinoma. In: Am J Physiol Renal Physiol, United States, F338-FP348, 2004.

43. Karhausen J, Kong T, Narravula S and Colgan SP: Induction of the von Hippel-Lindau tumor suppressor gene by late hypoxia limits HIF-1 expression. J Cell Biochem 95: 1264-1275, 2005. 